Y. MU, T. T. NGUYEN, M. J. KOH, R. R. SCHROCK, A. H. HOVEYDA* (BOSTON COLLEGE, CHESTNUT HILL AND MASSACHUSETTS INSTITUTE OF TECHNOLOGY, CAMBRIDGE, USA) $E$ - and $Z$-, Di- and Tri-substituted Alkenyl Nitriles through Catalytic Cross-Metathesis

Nat. Chem. 2019, 11, 478-487.

\title{
Di- and Tri-substituted Alkenyl Nitriles
}

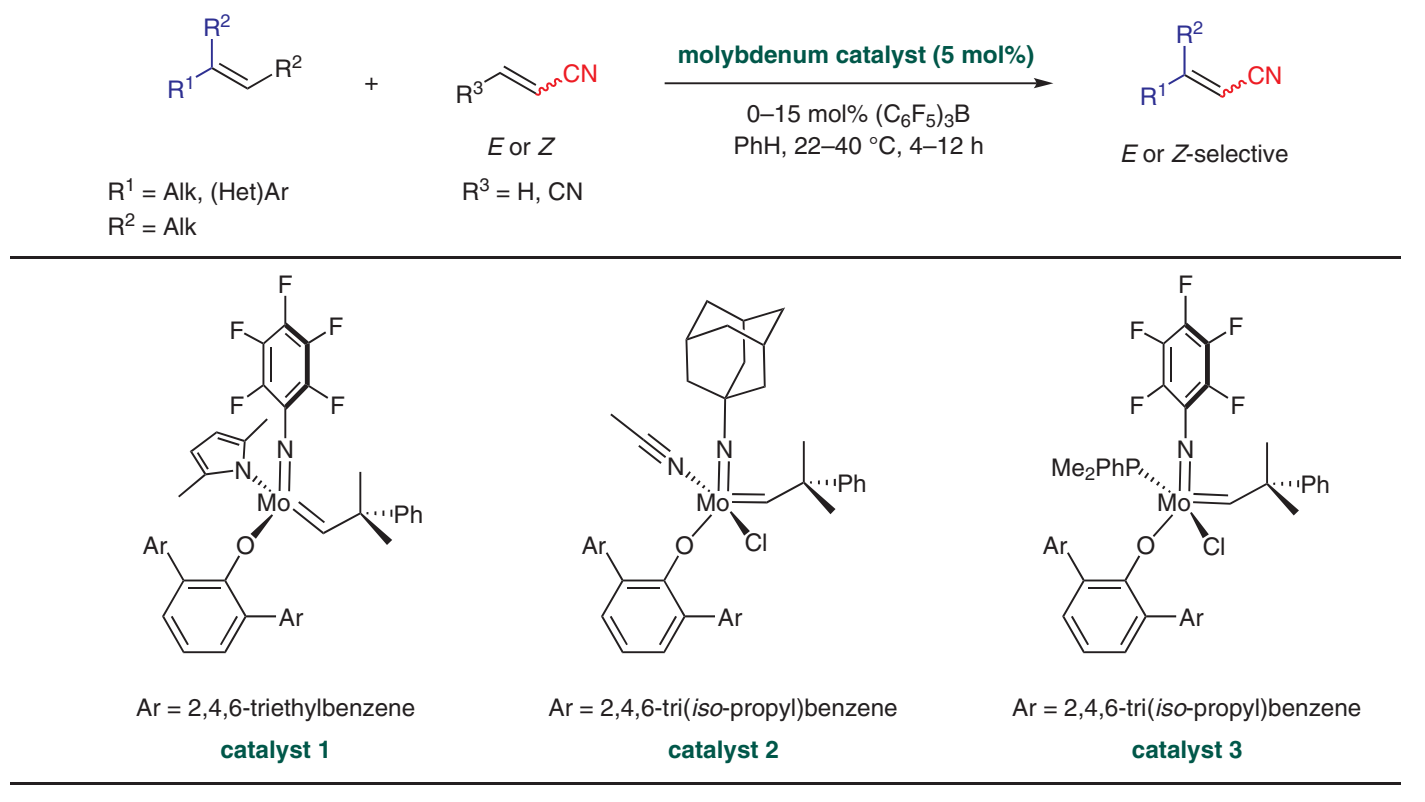

with catalyst 1 :<smiles>C/C=C\CCCCCC[13CH2]</smiles>

$77 \%$ yield, $Z / E>98: 2$<smiles>N#C/C=C\CCCCCCC#CS</smiles>

$78 \%$ yield, $Z$ IIE > 98:2

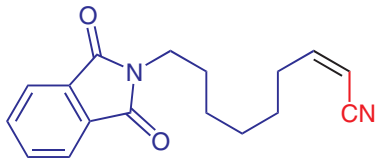

$86 \%$ yield, $Z$ ZIE $>98: 2$

with catalyst 2 :<smiles></smiles>

$90 \%$ yield, $Z / E>98: 2$<smiles>FC(F)(F)c1ccc(/C=C\C2CCCC2)cc1</smiles>

$77 \%$ yield, ZIE > 98:2

\section{Category}

Metals in Synthesis

\section{Key words}

alkenyl nitriles

cross-metathesis

molybdenum

catalysis

\section{Synfact
of the of the}

with catalyst 3 :<smiles>C/C=C(/C)CCc1ccccc1</smiles>

$82 \%$ yield, $Z / E=92: 8 E: Z$

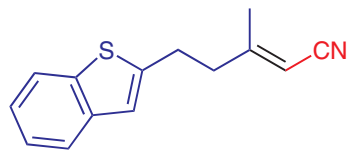

$58 \%$ yield, $Z / E=92: 8$

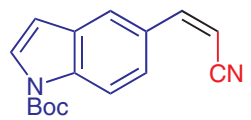

$92 \%$ yield, $Z / E=92: 8$
Significance: Hoveyda and co-workers disclose the preparation of $E$ - and Z-multiply-substituted alkenyl nitriles in high yields and excellent diastereoselectivities through molybdenum-catalyzed cross-metathesis reactions.
Comment: The choice of the molybdenum catalysis discussed in detail and the application of the methodology is demonstrated by the preparation of a wide range of biologically active substrates. 